\title{
Educational outreach and collaborative care enhances physician's perceived knowledge about Developmental Coordination Disorder Robin Gaines* ${ }^{* 1,2,3}$, Cheryl Missiuna ${ }^{\dagger 2}$, Mary Egan ${ }^{3}$ and Jennifer McLean ${ }^{4}$
}

Address: ${ }^{1}$ Children's Hospital of Eastern Ontario Research Institute, 401 Smyth Road, Ottawa, K1H 8L1, Ontario and School of Rehabilitation Sciences, University of Ottawa, Ontario, Canada, ${ }^{2}$ School of Rehabilitation Science and CanChild, Centre for Childhood Disability Research, McMaster University, Hamilton, Ontario, Canada, ${ }^{3}$ School of Rehabilitation Sciences, University of Ottawa, Ontario, Canada and ${ }^{4}$ Department of Pediatrics, Dalhousie University, Halifax, Nova Scotia and IWK Health Centre, Halifax, Nova Scotia, Canada

Email: Robin Gaines* - gaines@cheo.on.ca; Cheryl Missiuna - missiuna@mcmaster.ca; Mary Egan - megan@uottawa.ca; Jennifer McLean - jennifer.mclean@iwk.nshealth.ca

* Corresponding author †Equal contributors

Published: 24 January 2008

BMC Health Services Research 2008, 8:21 doi:10.1 186/1472-6963-8-21
Received: 26 September 2007

Accepted: 24 January 2008

This article is available from: http://www.biomedcentral.com/ |472-6963/8/2 I

(C) 2008 Gaines et al; licensee BioMed Central Ltd.

This is an Open Access article distributed under the terms of the Creative Commons Attribution License (http://creativecommons.org/licenses/by/2.0), which permits unrestricted use, distribution, and reproduction in any medium, provided the original work is properly cited.

\begin{abstract}
Background: Developmental Coordination Disorder (DCD) is a chronic neurodevelopmental condition that affects 5-6\% of children. When not recognized and properly managed during the child's development, DCD can lead to academic failure, mental health problems and poor physical fitness. Physicians, working in collaboration with rehabilitation professionals, are in an excellent position to recognize and manage DCD. This study was designed to determine the feasibility and impact of an educational outreach and collaborative care model to improve chronic disease management of children with DCD.

Methods: The intervention included educational outreach and collaborative care for children with suspected DCD. Physicians were educated by and worked with rehabilitation professionals from February 2005 to April 2006. Mixed methods evaluation approach documented the process and impact of the intervention.

Results: Physicians: 750 primary care physicians from one major urban area and outlying regions were invited to participate; 147 physicians enrolled in the project. Children: 125 children were identified and referred with suspected DCD. The main outcome was improvement in knowledge and perceived skill of physicians concerning their ability to screen, diagnose and manage DCD. At baseline $91.1 \%$ of physicians were unaware of the diagnosis of DCD, and only $1.6 \%$ could diagnose condition. Post-intervention, $91 \%$ of participating physicians reported greater knowledge about DCD and $29.2 \%$ were able to diagnose $D C D$ compared to $0.5 \%$ of non-participating physicians. $100 \%$ of physicians who participated in collaborative care indicated they would continue to use the project materials and resources and $59.4 \%$ reported they would recommend or share the materials with medical colleagues. In addition, $17.6 \%$ of physicians not formally enrolled in the project reported an increase in knowledge of DCD.

Conclusion: Physicians receiving educational outreach visits significantly improved their knowledge about $\mathrm{DCD}$ and their ability to identify and diagnose children with this condition. Physicians who collaborated with occupational therapists in providing care reported more confidence in diagnosing children with DCD and were more likely to continue to use screening measures and to provide educational materials to families.
\end{abstract}




\section{Background}

Developmental Coordination Disorder (DCD) is a chronic neurodevelopmental condition that affects 5-6\% of children [1]. No generally accepted definition of this condition was available until 1989 [2]. The relatively recent inclusion of this diagnosis in the Diagnostic and Statistical Manual of Mental Disorders may explain the difficulty that many parents experience obtaining an accurate diagnosis when their children present with significant motor problems that impact on everyday activities [3].

Recognition of this disorder is critical. Due to their motor incoordination, these children are frustrated in schoolwork, self-care, sports and recreation. To the untrained, these difficulties often appear to be the result of immaturity, laziness, or uncooperative behavior $[4,5]$. When unrecognized and unmanaged, DCD can lead to longterm negative consequences including academic failure, $[6,7]$ poor social relationships, $[8,9]$ emotional difficulties, $[10,11]$ mental health problems, [12] and poor physical fitness $[13,14]$.

Physicians have ongoing contact with their young patients and are trusted by parents as the first resource for health care and referral to other providers. Therefore, physicians are in an optimal position to support families over time. Physicians can effectively manage DCD by recognizing and communicating a diagnosis to the family and then monitoring and supporting the family in the long term management of the child's healthcare needs. Physicians have the expertise to collect a detailed history, conduct a physical and neurological examination to rule out other causes of motor coordination. These steps are necessary in providing a differential diagnosis of DCD. However, at present, lack of physician knowledge about DCD is a major barrier to effective management of this chronic condition. To improve this knowledge gap, we designed and evaluated a demonstration project to enhance primary care physicians' ability to manage this under-recognized, but common childhood condition.

It is well-established that increasing health provider knowledge requires multi-faceted, interactive and repeated interventions [15-17]. Interventions such as educational outreach (personalized visits to a health care provider in his or her own setting) are particularly responsive to the specific information needs of the practitioner [18]. While research has demonstrated the effectiveness of educational outreach, the addition of collaborative care (in which another health professional provides specialized assessment and shares the process of supporting the family with the physician) may have promise for improving the management of chronic developmental disorders. Rehabilitation professionals, particularly occupational therapists (OTs) who have expertise in evaluating and enhancing motor-based functional activity, may be key members of such a collaborative health care team for physicians and children with DCD.

This demonstration project was conducted to determine the impact of a program, offering educational outreach and collaborative care, to improve identification and management of children with DCD by primary care physicians.

\section{Methods \\ Study design}

A mixed methods evaluation approach which employed pre- and post-project surveys, quantitative measures, questionnaires and focus groups was used to evaluate this demonstration project [19]. Approval for this study was granted by the Children's Hospital of Eastern Ontario Research Ethics Board.

\section{Participants}

Community physicians, including community-based pediatricians and family medicine physicians, were recruited during information sessions using a faxed letter to the 750 primary care physicians practicing in the region. Physicians who joined the study were able to select from, and participate in, a number of educational outreach activities described below. Following education, participating physicians were able to refer children aged 4-12 years to the study for collaborative care if they suspected the child may have DCD, and had ruled out other potential explanations for the motor problems (e.g., head trauma, muscular dystrophy).

\section{Intervention}

\section{Educational outreach}

A multi-faceted approach was used [16]. Educational materials for physicians were developed systematically, working with primary care physicians and representatives of the College of Family Physicians [20]. An inter-professional team including a developmental pediatrician, speech-language pathologist and psychologist provided informational support to an occupational therapist (OT) who worked in the community. The OT provided education to physicians in their offices using an array of materials that were developed for the project including: userfriendly, evidence-based written information presented in a binder; reminder folders which prompted physicians to carry out the stages of the screening process; tear-off interview guides; a parent-friendly waiting room advertisement, as well as a DVD presenting typical motor behaviour of children with and without DCD. Project information, sample video clips and materials were also made available electronically [21] (username: dcdpack; password: dcdchild). These materials are still available and continue to be used by physicians as a resource 
(please see Additional file 1 for details of physician educational materials).

The OT tailored the educational opportunities for each physician according to learning needs and style, background, interests, time availability and preference for group or individual meetings.

\section{Collaborative care}

Participating physicians were invited to apply their new knowledge in their practice to screen their patients and then refer any child suspected as having DCD to the OT for further evaluation. The OT administered the Movement Assessment Battery for Children [22], a test of motor impairment, and then interviewed the parent about the impact of the child's motor abilities on functional activities. Each child was screened using the Kaufmann Brief Intelligence Test-2 (K-BIT) [23] to rule out significant global developmental delay as the cause of motor difficulties. Following the assessment, the OT provided a summary of the results to the physician to assist him/her in determining whether a diagnosis of DCD was appropriate.
Tailoring services to the physician's needs, the OT assessed the child either with or without the physician present, provided feedback in written form and discussed the results with the physician. The OT and the physician then jointly presented the findings to the parents. A wide variety of educational materials was made available to parents at this time including handouts that could be shared with teachers, coaches, community leaders and other physicians. (See Additional file 1 for details of these family educational materials). Materials were available in English and French and were selected by the OT and physician based upon the child's identified needs. OT collaborative care services including conducting a clinical assessment with child and family, consultation with the physician and provision of feedback to the family, took between 3 and 4 hours per child in total. A physician's involvement in collaborative care including screening of the child's motor abilities, discussion with the family, consultation with the OT and provision of feedback took between 1 and 3 hours per child. The process of educational outreach and collaborative care is illustrated in Figure 1.

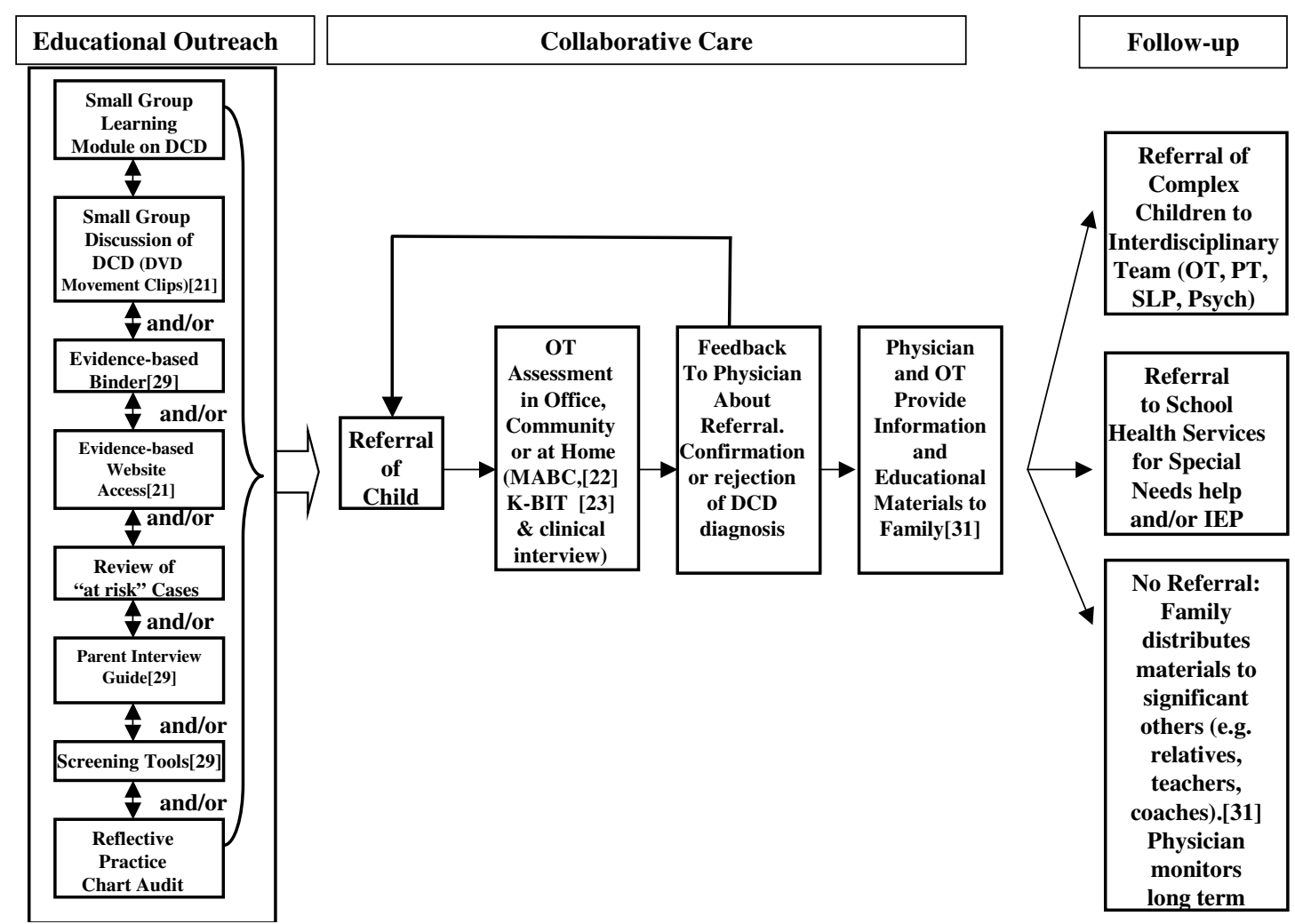

Figure I

Educational Outreach \& Collaborative Care. MABC = Movement Assessment Battery for Children; K-BIT = Kaufman Brief Intelligence Test; OT = Occupational Therapist; PT = Physiotherapist; Psych = Psychologist; SLP = Speech/Language Pathologist; IEP = Individualized Educational Plan 


\section{Impact measurement}

The impact of the demonstration project was evaluated in a number of ways. First, the number of physicians who chose to participate in the project, within the timeframe offered, is regarded as an indicator of the interest and need for educational outreach on this topic of DCD. Second, the number of children who were suspected of having DCD, referred to OT, received collaborative care and were given a diagnosis of DCD, is regarded as a measure of the effectiveness of the educational outreach.

To determine whether or not there was any change in physician awareness of DCD, a baseline survey of all physicians in the Ottawa region was used to establish their preproject level of knowledge and perceived skill in diagnosing children with DCD. An identical post-project survey was conducted at project completion. In both surveys, physicians were asked to indicate one statement that best described their knowledge about DCD and one statement that best described their skills in recognizing and diagnosing a child with DCD. Responses were scored on a scale of 1 to 7 , with 1 representing the least knowledge and skill and 7 representing the greatest knowledge and skill. In the second survey, participant physicians' responses were compared with responses from non-participating physicians throughout the region.

Participating physicians also completed two post-intervention questionnaires. In the first questionnaire they were asked questions about the perceived usefulness of the educational tools (e.g., screening activities, parent interview guide, family educational materials) and contribution of education and child-specific information from the OT. In the second questionnaire they were asked to indicate whether they planned to continue using the materials and/or share them with their colleagues.

Impact of the project on participating physicians was also examined qualitatively through focus groups. Only those physicians who had completed the educational outreach and had worked in collaborative care with the OT by the time of the focus group were invited to participate. Physicians were invited to a focus group according to their specialty (i.e. family medicine or paediatrics). All focus groups were audio-recorded and transcribed verbatim.

\section{Analysis}

Quantitative results of the questionnaires are presented descriptively. Data from the questionnaire asking physicians to report on usefulness are summarized so that response scores of $1-4$ are judged to be negative, and scores of 5-7 positive. Focus group findings were contentanalyzed using methods recommended by Krueger and Casey [24].

\section{Results}

Of the 750 physicians (678 family physicians and 72 community paediatricians) in the Ottawa region who were invited to participate, 147 physicians enrolled in the study over a 14 month period (see Table 1). Eighty four outreach visits were provided to these physicians by the OT for purely educational purposes: these included small group educational sessions and one-on-one discussions with physicians. In the majority of cases, these sessions occurred before the participating physicians referred children to the project. The median length of a 'face-to-face' visit with a physician was 45 minutes (range $=1$ to 120 minutes).

Sixty-four of the 147 physicians ( 44 family physicians and 20 community pediatricians) referred at least one child to the OT for assessment and collaborative care. Initially, physicians were limited to 3 referrals; however, as the study progressed, a few physicians asked if they could refer additional children and this was permitted. The number of children referred for collaborative care by each physician ranged from $1-5$, mode $=1$. A total of 125 children were referred and, of these children, 116 (92.8\%) met the study inclusion criteria and were assessed by the OT. Children who were not seen were excluded due to age cut-off, previous diagnosis of other conditions (e.g., autism), and/ or evidence of neurological conditions (e.g., seizure disorder). The age of children who received collaborative care ranged from 48 - 153 months $(X=96.3$ months $)$ and 87 $(75 \%)$ were male.

Table I: Physician participants

\begin{tabular}{ll}
\hline PHYSICIANS (n = I47) & \\
\hline Male/Female & $47(32 \%) / 100(68 \%)$ \\
Community pediatricians & $30(20.4 \%)$ \\
Family Physicians & $117(79.6 \%)$ \\
Type of Primary Care Practice: & \\
Group & $100(68 \%)$ \\
Sole practitioner or with partner & $36(24.6 \%)$ \\
Not reported & $11(7.4 \%)$ \\
Community-based practice & $136(92.6 \%)$ \\
Community \& hospital practice & $11(7.4 \%)$ \\
Years in practice: & \\
$<$ II years & $44(29.9 \%)$ \\
II-20 years & $57(38.8 \%)$ \\
$>20$ years & $35(23.8 \%)$ \\
Not reported & $1 \mathrm{I}(7.5 \%)$ \\
Number of children seen annually: & \\
$<200$ children/year & $59(40.1 \%)$ \\
$200-500$ children/year & $28(19.0 \%)$ \\
$>500$ children/year & $30(20.4 \%)$ \\
Don't know & $10(6.8 \%)$ \\
Not reported & $20(13.6 \%)$ \\
\hline
\end{tabular}


Following assessment by the OT, 16 children (13.8\%) were determined not to have motor delays substantial enough to warrant a diagnosis of DCD, according to study criteria. Cut-offs were based upon DSM IV diagnostic criteria [1], and are outlined in more detail elsewhere [25]. Another 12 children (10.3\%) were determined to have motor impairment that was better explained by other conditions (orthopedic (1), trauma (3), and generalized delay (8)). The remaining $88(76 \%)$ met research criteria for DCD; all but one were subsequently given a clinical diagnosis of DCD by their physician. In the one exception, the physician felt that environmental factors such as limited exposure to motor activities and family situation may have been the primary cause of the child's motor difficulties. The family did not return for consultation with the family physician, so further exploration of developmental versus environmental issues was not possible.

Pre-project knowledge and skill surveys were sent out to all 750 primary care physicians in the region. With a return rate of $25 \%$ (191 physicians), $91.1 \%$ of physicians reported that they were unaware of the condition of DCD and only $1.6 \%$ reported that they felt able to diagnose children with the condition. Post-project, the same survey was sent to all 750 physicians in the region, including physicians who had participated in the project and those who did not join the study. Two hundred and seventy-six questionnaires were returned for an overall regional return rate of $37 \%$. The return rate for participating physicians was $61 \%(89 / 147)$ and $31 \%(187 / 603)$ for non-participating physicians. Table 2 depicts the results from the post-project questionnaire, asking physicians to describe their knowledge about DCD and their skill in making the DCD diagnosis. Results indicate that $91 \%$ of physicians who received educational outreach and responded to the questionnaire reported that they have knowledge about DCD in comparison with non-participating physicians in the same community among whom only $17.6 \%$ reported familiarity with the condition. In response to the perceived skill question, $41.6 \%$ of participating physicians reported an ability to diagnose children who had DCD, while only $3.2 \%$ of non-participating physicians believed that they could make this diagnosis.

Results of the post-project questionnaire asking physicians to rate the usefulness of the diagnostic tools and collaborative care process are presented in Table 3. Questionnaire responses are reported from the 33 physicians who received educational outreach and participated in collaborative care with the OT and the 54 physicians who received educational outreach, but did not refer a child.

Responses to questions asking physicians about their plans for continued use of the project materials were received from 32 physicians who received educational outreach and collaborative care, and from 52 physicians who received educational outreach only. All $(100 \%)$ of physicians answering this question $(\mathrm{n}=32)$ who received both services indicated that they would continue to use project materials and resources, and $59.4 \%(\mathrm{n}=19)$ reported that they would recommend/share the materials with a medical colleague. Most $(90.4 \%)(n=47)$ of the 52 responding physicians who received educational outreach only indicated that they would continue to use the project materials and $28.8 \%(n=15)$ reported that they would recommend the materials to their colleagues.

Table 2: Knowledge and skills as reported by physician participants and physicians in the region, after project completion

\section{PHYSICIAN QUESTIONNAIRE}

Participating Physicians

$\mathrm{n}=89$
Non-Participating Physicians $\mathrm{n}=187$

\section{KNOWLEDGE}

Never heard/Limited Knowledge

Familiar with DCD

$8(9 \%)$

$81(91 \%)$

$145(77.5 \%)$

No response

$33(17.6 \%)$

$9(4.8 \%)$

\section{SKILLS}

Not able to recognize child with DCD

Observe motor skill difficulties, but do not discuss with parents

Can screen for motor difficulties but would refer to specialist

Able to diagnose $\mathrm{DCD}$

No response

$\begin{array}{ll}4(4.5 \%) & 45(24.1 \%) \\ 6(6.7 \%) & 41(21.9 \%) \\ 38(42.7 \%) & 82(43.9 \%) \\ 37(41.6 \%) & 6(3.2 \%) \\ 4(4.5 \%) & 13(6.9 \%)\end{array}$


Table 3: Usefulness of project activities, as reported by physician participants*

\begin{tabular}{lll}
\hline Evaluation of Intervention & $\begin{array}{l}\text { Educational outreach and collaborative } \\
\text { care }(\mathrm{N}=33) . \mathrm{N} \text { and \% reporting positive } \\
\text { usefulness } * *\end{array}$ & $\begin{array}{l}\text { Educational outreach only } \\
(\mathrm{N}=54) . \mathrm{N} \text { and \% reporting } \\
\text { positive usefulness** }\end{array}$ \\
\hline $\begin{array}{l}\text { How useful has the project been in helping you learn to identify } \\
\text { children with DCD? }\end{array}$ & $33(100 \%)$ & $28(51.9 \%)$ \\
$\begin{array}{l}\text { How useful are the DCD screening activities in your } \\
\text { examination? }\end{array}$ & $26(78.8 \%)$ & $23(42.6 \%)$ \\
$\begin{array}{l}\text { How useful is administering the parent interview guide? } \\
\text { How useful has the project been in helping you diagnose } \\
\text { children with DCD? }\end{array}$ & $25(75.8 \%)$ & $22(40.7 \%)$ \\
$\begin{array}{l}\text { How useful has it been to share responsibility for identification } \\
\text { and management of a child in your practice with an OT? }\end{array}$ & $31(97 \%)$ & $\mathrm{n} / \mathrm{a}$ \\
\hline
\end{tabular}

*Usefulness questionnaires were completed by $87 / 147$ (59.2\%) of participants

**Responses to each question were scored on a scale of I to 7 with I representing 'not very useful' and 7 representing 'highly useful'. Positive was determined to be scores of $5-7$.

\section{Focus group results}

Twenty four physicians (9 Family Physicians and 15 Pediatricians) who had completed both educational outreach and collaborative care at the time of the focus group were invited to attend. Four physicians attended the family medicine focus group and 13 physicians attended the paediatrician focus group. Physicians reported 'lack of availability' as their reason for not participating in the focus groups. Analysis of the transcripts indicated that both family physicians and pediatricians noted that they now had an increased awareness of the possible presence of DCD and had introduced regular screening techniques into their practices. These techniques ranged from routinely asking parents if they felt their children were "clumsy", observing the child taking off a shirt, or asking parents to complete a short questionnaire. As one pediatrician remarked, "It seems that all these kids are in my practice, I just didn't identify them before".

Both groups of physicians reported appreciating the opportunity to have a more in-depth evaluation by the OT of children whom they had screened as having possible DCD. Many in the pediatrician group found this evaluation critical for children whose difficulties appeared marginal on screening. "The ones you [identify on screening] are the obvious ones, but the ones that are in between, do they need it, do they not need it, where do you make the cut off point? You really need someone who can actually do that fine-tuning...We don't have time to do that."

Both groups of physicians found the educational outreach valuable. Family physicians were enthusiastic about the tools for screening and the educational materials for families. For example, one family physician noted, "I' $m$ doing counseling, I'm telling the mom various different sports that might be better for them, where they succeed, where they may also develop some other skills...instead of setting them up for another failure. I think that's very important, and I've been doing that in the context of a physical. " Another family physician identified a role for herself in the context of public education and remarked that she was now sharing the information about DCD with adult patients and friends who are teachers.

\section{Discussion}

The results of this study suggest that educational outreach and collaborative care provided within a primary care setting had a substantial impact on physicians' knowledge about children with DCD. There are very few examples in the literature of multidisciplinary or collaborative care approaches designed to increase the ability of primary care physicians to manage chronic childhood developmental disorders. In one recent study by Connor [26], primary care pediatricians were assisted by child psychiatrists to improve their evaluation and management of ADHD, childhood depression or anxiety disorders. A multidisciplinary/coordinated approach has also been reported for the management of individuals with Down Syndrome [27]. To the extent of our knowledge, there have been no other studies of the impact of a rehabilitation professional providing educational outreach in primary care settings to enhance physician knowledge and skills about a chronic childhood condition.

Increases in physician-reported comfort in managing children with common psychosocial and mental health problems, such as ADHD or social-emotional difficulties, have been shown to be positively related to receiving continuing medical education [28]. Primary care physicians have suggested that innovative programs improve their confidence and help modify their attitudes about the importance of childhood mental health problems [28]. Physician attitudes and confidence were not directly measured in our project; however, a substantial increase in reported knowledge and skill was found for participating physicians, as compared with physicians in the region 
who did not receive educational outreach. Of interest, physicians who worked directly with the OT in providing collaborative care for a particular child reported even greater knowledge and enhanced skill. In addition, these physicians reported that they were more likely to share the information with their colleagues. Active collaboration with another health professional, as an additional feature of the continuing education process, may be optimal for knowledge uptake about these types of conditions.

\section{Limitations of the study}

Study limitations may restrict the generalizability of our results. There was a dramatic gain in perceived knowledge and skill among physicians who received these services compared to those who did not. It is possible that these participants may have represented a group of highly motivated physicians, who would have worked independently to develop their knowledge and skill when they encountered a diagnosis with which they were unfamiliar. However, it is unlikely that such self-selection bias accounted for all of the difference between physicians who received outreach and collaboration and those who did not, as resources about DCD had been available before this project began.

Second, the physicians who self-referred to this study may not be a representative sample. In this study, the majority of the physician participants (68\%) were women. While the proportion of women in medicine is increasing, female physicians remain a minority in Ontario and among them a large proportion are relatively recently qualified. It is possible that female and more recently qualified physicians may be more open to collaborative practice and outreach education from other professionals.

While we are unable to make a definitive statement about the size of the effect of this intervention in other regions, this project demonstrates the feasibility and potential impact of outreach education and collaborative care with rehabilitation professionals to improve the management of children with this chronic condition.

\section{Conclusion}

Ideally, best practice in service provision for children with chronic conditions is evidence-based. It can be difficult for primary care physicians to remain current about screening practices and management concerning all chronic childhood conditions. Rehabilitation professionals have a 'specialized' knowledge set that is often more focused in scope. Integration of these professionals into primary care settings allows for current knowledge about identification and management of chronic childhood conditions to be shared with physicians. The actual cost of implementing a model of care such as this is difficult to determine. Physicians who participated in this project were not reimbursed in any way for their time but joined the project in order to gain new knowledge. Comments raised during focus group sessions suggest that primary care physicians have an awareness of the presence of these children in their practices but may not have previously known how to respond to parents' concerns. Missiuna and colleagues [3] have previously demonstrated the high cost, to the family and to the healthcare system, of parents being referred by their physician to one specialist after another, seeking information that would help them understand the difficulties being experienced by their child with DCD. When the family physician is knowledgeable enough to respond and can work with an OT to provide collaborative care, it is probable that the needs of children and families would be met in a more timely and effective manner, and at a lower cost.

It is possible that the model of educational outreach and collaborative care used in this project may be applicable for improving physicians' identification and management of other chronic childhood conditions first identified in primary care settings. Autism, attention deficit hyperactivity disorder, chronic obesity, and specific language impairment are examples of conditions about which rehabilitation providers (speech/language pathologists, occupational therapists, physiotherapists, psychologists) may be able to share knowledge that would support physicians in their provision of high quality, evidence-based care. Further studies of educational outreach are needed to look at the types of information and patients who may be served by these professionals.

\section{Competing interests}

The author(s) declare that they have no competing interests.

\section{Authors' contributions}

All authors have read and approved the final manuscript.

RG had full access to all of the data in the study and takes responsibility for the integrity of the data and the accuracy of the data analysis.

Study concept and design: RG, CM.

Acquisition of data: RG.

Analysis and interpretation of data: RG, CM, ME, JMcL.

Drafting of the manuscript: RG, CM, ME, JMcL.

Critical revision of the manuscript for important intellectual content: RG, CM, ME, JMcL. 
Statistical analysis: RG, CM, ME.

Obtained funding: RG, CM, ME, JMcL.

Administrative, technical, or material support: RG, CM, ME, JMcL.

Study supervision: RG, CM, ME, JMcL.

\section{Additional material}

\section{Additional file 1}

Physician and family educational materials. detailed description of materials and references for finding them.

Click here for file

[http://www.biomedcentral.com/content/supplementary/14726963-8-21-S1.doc]

\section{Acknowledgements}

We would like to acknowledge Dr. Richard Handfield-Jones, Director of Continuing Medical Education, University of Ottawa, for suggesting the inclusion of a baseline survey of physician knowledge in the project design. The authors wish to thank Denise DeLaat, Occupational Therapist, for her tireless efforts on the project and Helen Soucie, Medical Writer, Children's Hospital of Eastern Ontario Research Institute, for her excellent assistance with manuscript preparation. The authors are grateful to the family physicians, especially Dr. Patricia Mousmanis, who contributed to the development of educational materials, and to the physicians, children and families who took part in the study.

This research was funded by a grant from the Ontario Ministry of Health and Long Term Care. We are grateful for the financial support and mentorship provided by the Children's Hospital of Eastern Ontario and the Children's Hospital of Eastern Ontario Research Institute; to CanChild for supporting the development of educational materials for families; and to Dr. Stuart Coupland for financing the cost of publishing this manuscript in an open access journal that is accessible to all.

The sponsors did not participate in the design or conduct of this study, in the collection, management, analysis, or interpretation of data, in the writing of the manuscript, or in the preparation, review, approval, or decision to submit this manuscript for publication.

Statements in this article should not be construed as endorsement by the Ontario Ministry of Health and Long Term Care, the Children's Hospital of Eastern Ontario, the Children's Hospital of Eastern Ontario Research Institute or CanChild. The authors of this study are responsible for its content.

\section{References}

I. American Psychiatric Association: Diagnostic and statistical manual of mental disorders 4th edition. Washington, DC: American Psychiatric Association; 2000.

2. American Psychiatric Association: Diagnostic and statistical manual of mental disorders 3rd edition. Washington, DC: American Psychiatric Association; 1989.

3. Missiuna C, Moll S, Law M, King S, King G: Mysteries and mazes: parents' experiences of children with developmental coordination disorder. Can J Occup Ther 2006, 73:7-I7.

4. Missiuna C, Moll S, King S, Law M, King G: "Missed and Misunderstood": Children with Developmental Coordination Disor- der in the School System. International Journal of Special Education 2006, 2 I:53-67.

5. Fox AM, Lent B: Clumsy children: Primer on developmental coordination disorder. Can Fam Physician 1996, 42: 1965-1971.

6. Dewey D, Kaplan BJ, Crawford SG, Wilson BN: Developmental coordination disorder: associated problems in attention, learning, and psychosocial adjustment. Hum Mov Sci 2002, $21: 905-918$.

7. Gillberg IC, Gillberg C: Children with preschool minor neurodevelopmental disorders. IV: Behaviour and school achievement at age I3. Dev Med Child Neurol 1989, 3 I:3-13.

8. Cantell MH, Smyth MM, Ahonen T: Clumsiness in adolescence: Educational, motor and social outcomes of motor delay at five years. APAQ 1994, I I: I I5- I 29.

9. Geuze R, Borger $\mathrm{H}$ : Children who are clumsy: Five years later. APAQ 1993, I0:10-21.

10. Piek JP, Dworcan M, Barrett N, Coleman R: Determinants of selfworth in children with and without developmental coordination disorder. The International Journal of Disability Development and Education 2000, 47:259-27l.

II. Skinner RA, Piek JP: Psychosocial implications of poor motor coordination in children and adolescents. Hum Mov Sci 200I, 20:73-94.

12. Sigurdsson E, Van Os J, Fombonne E: Are impaired childhood motor skills a risk factor for adolescent anxiety? Results from the 1958 U.K. birth cohort and the National Child Development Study. Am J Psychiatry 2002, I 59: 1044-I046.

13. Cairney J, Hay JA, Faught BE, Hawes R: Developmental coordination disorder and overweight and obesity in children aged 9-I 4 y. Int J Obes (Lond) 2005, 29:369-372.

14. Raynor AJ: Strength, power and co-activation in children with developmental coordination disorder. Dev Med Child Neurol 2001, 43:676-684.

15. Grimshaw JM, Shirran L, Thomas R, Mowatt G, Fraser C, Bero L, Grilli $R$, Harvey E, Oxman A, O'Brien MA: Changing provider behavior: an overview of systematic reviews of interventions. Med Care 2001, 39:112-45.

16. Oxman AD, Thomson MA, Davis DA, Hayes JE: No magic bullets: A systematic review of 102 trials of interventions to improve professional practice. CMAJ 1995, I53:|423-|43I.

17. Davis D, O'Brien MAT, Freemantle N, Wolf FM, Mazmanian P, Taylor-Vaisey A: Impact of formal continuing medical education: Do conferences, modules, rounds and other traditional continuing education activities change physician behavior or health care outcomes? Journal of the American Medical Association 1999, 282:867-874.

18. O'Brien MA, Rogers S, Jamtvedt G, Oxman AD, Odgaard-Jensen J, Kristoffersen DT, Forsetlund L, Bainbridge D, Freemantle N, Davis DA, Haynes RB, Harvey EL: Educational outreach visits: effects on professional practice and health care outcomes. Cochrane Database Syst Rev 2007, I 7(4):CD000409.

19. Cresswell JW, Fetters MD, Ivankova NV: Designing a Mixed Methods Study in Primary Care. Annals of Family Medicine 2004, 2:7-I 2.

20. Missiuna $C$, Gaines $R$, Soucie $H$ : Why every office needs a tennis ball: a new approach to assessing the clumsy child. Can Med Assoc J 2006, I 75:47|-473.

21. Developmental Coordination Disorder - A new look at the physically awkward child [http://www.dcdpack.ca]

22. Henderson SE, Sugden DA: Movement Assessment Battery for Children London: The Psychological Corporation; 1992.

23. Kaufmann AS, Kaufmann NL: Kaufman Brief Intelligence Test 2nd edition. Circle Pines, Minnesota: American Guidance Service Inc; 2004.

24. Krueger RA, Casey MA: Focus Groups: A Practical Guide for Applied Research 3rd edition. Thousand Oaks: CA: Sage; 2000.

25. When primary care physicians identify children with $D C D$, who do they find? [http://www.canchild.ca/Portals/0/Intranet/ DCD/PDF/CHEO-posterDCDflowchrt-final.pdf]

26. Connor DF, McLaughlin TJ, Jeffers-Terry M, O'Brien WH, Stille CJ, Young LM, Antonelli RC: Targeted child psychiatric services: a new model of pediatric primary clinician - child psychiatry collaborative care. Clin Pediatr (Phila) 2006, 45:423-434.

27. Heerensperger D: Provision of coordinated care for individuals with Down syndrome: the Calgary perspective. Downs Syndr Res Pract 2006, I0:4-9.

28. Miller AR, Johnston C, Klassen AF, Fine S, Papsdorf M: Family physicians' involvement and self-reported comfort and skill in 
care of children with behavioral and emotional problems: a population-based survey. BMC Fam Pract 2005, 6: 12.

29. Missiuna C, Gaines R: The DCD Physician Allied Health Collaboration Kit (DCD PACK) Hamilton, Ontario: Mc Master University: CanChild Centre for Childhood Disability Research; 2004.

30. Missiuna C: Does your child have DCD? Today's Kids in Motion 2003, 4:22-24.

31. CanChild - Centre for Childhood Disability Research [http:/ /www.canchild.ca]

\section{Pre-publication history}

The pre-publication history for this paper can be accessed here:

http://www.biomedcentral.com/1472-6963/8/21/prepub
Publish with Biomed Central and every scientist can read your work free of charge

"BioMed Central will be the most significant development for disseminating the results of biomedical research in our lifetime. " Sir Paul Nurse, Cancer Research UK

Your research papers will be:

- available free of charge to the entire biomedical community

- peer reviewed and published immediately upon acceptance

- cited in PubMed and archived on PubMed Central

- yours - you keep the copyright

Submit your manuscript here:

http://www.biomedcentral.com/info/publishing_adv.asp 